\title{
No Association between the Response to Methylphenidate and DRD4 Gene Polymorphism in Korean Attention Deficit Hyperactivity Disorder: ACase Control Study
}

\author{
Hyun Soo Ji ${ }^{1,2}$, Ki Chung Paik ${ }^{1,2}$, Woo Sung Park ${ }^{1,3}$, Myung Ho Lim ${ }^{1,2}$ \\ ${ }^{1}$ Environmental Health Center, Dankoook University Hospital, Cheonan, Departments of ${ }^{2}$ Psychiatry and ${ }^{3}$ Pediatrics, Dankook University \\ College of Medicine, Cheonan, Korea
}

\begin{abstract}
Objective: Recently the relationship between alleles frequency distribution, drug response and the attention deficit hyperactivity disorder (ADHD), has been actively researched. We investigated the association between the genetic type, alleles and drug response for the dopamine receptor D4 (DRD4) gene in ADHD patients in Korea.

Methods: One hundred fourteen patients diagnosed with ADHD according to the the Diagnostic and Statistical Manual of Mental Disorders version IV (DSM-IV) diagnostic criteria were selected for the study. The clinical features of patients were confirmed by Korean version of Conners' parent rating scale, Attention deficit Diagnostic System, Korean version of Spielberger state-trait anxiety scale. Blood samples were taken from the 198 subjects. DNA was extracted from blood lymphocytes, PCR was performed for DRD4 Polymorphism. Alleles, genotype frequencies, the Clinical Global Impression (CGI) improvement score were compared using the chi-square test. Korean ADHD Rating Scale (K-ARS) and CGl severity scores were compared using the t-test. Results: In comparing the ADHD with 4/4 repeats group and without the ADHD with 4/4 repeats group, no significant difference was seen between the DRD4 genetic type, alleles distribution, and CGl drug response.

Conclusion: As a result, it is viewed that there is no relationship between ADHD and DRD4, but final decision is indefinite. Follow up studies with larger patient or pure subgroups are expected.
\end{abstract}

KEY WORDS: Attention deficit hyperactivity disorder; DRD4 polymorphism; Case control studies; Drug response; MethyIphenidate.

\section{INTRODUCTION}

Attention deficit hyperactivity disorder (ADHD), which is a neurodevelopmental disorder characterized by inattention, hyperactivity and impulsivity behavior, is a common disorder that has about $3-5 \%$ prevalence rate among prepubertal elementary school children (American Psychiatric Association, 1994). Recent family study shows that ADHD has an $80-90 \%$ hereditability, ${ }^{1)}$ accordingly molecular genetic studies are being actively carried out. Most of the ADHD studies are being done on the enzyme or receptor related genes in the dopaminergic neurotransmission pathways, because symptoms of ADHD show a 70\% improvement upon treatment with the psy-

\footnotetext{
Received: July 16, 2012 / Revised: August 28, 2012

Accepted: August 29, 2012

Address for correspondence: Myung Ho Lim, MD

Department of Psychiatry, Dankook University Medical College, 359

Manghyang-ro, Cheonan 330-715, Korea

Tel: +82-41-550-3945, Fax: +82-41-561-3007

E-mail: paperose@dku.edu
}

chostimulants such as methylphenidate (MPH). ${ }^{2)}$ The dopamine receptor D4 (DRD4) gene has also been regarded as a leading candidate gene for ADHD. DRD4 maps to chromosome $11 \mathrm{p} 15.5$ and displays a high degree of variability at the 48-bp variable number tandem repeat (VNTR) on exon 3, which can be 2-11 times. ${ }^{3)}$

Association between the 7 repeat allele of a VNTR within the coding region of DRD4 and ADHD has been studied by several groups. LaHoste $e t$ al. ${ }^{4)}$ were the first report an increased frequency of DRD4 7 repeats (22\% vs. 9\%) in ADHD children. These findings were subsequently replicated in Coucasian children mainly. But there were few studies conducted in Asian ADHD children, no 7 repeats allele has been founded. ${ }^{5,6}$ Leung et al. ${ }^{5)}$ reported firstly in eastern area a significantly increased prevalence of the 2-repeat allele at DRD4 in Chinese ADHD children, whereas none of them had the DRD4 7-repeat allele. Seeger t al. $^{7)}$ reported that the presence of the 7-repeat allele of the DRD4 gene seems to be associated with a poor response to MPH treatment in ADHD. In addition,

(c) This is an Open-Access article distributed under the terms of the Creative Commons Attribution Non-Commercial License (http://creativecommons.org/licenses/by-nc/3.0) which permits unrestricted non-commercial use, distribution, and reproduction in any medium, provided the original work is properly cited. 
Hamarman et al.$^{8)}$ reported that ADHD children possessing the DRD4 7-repeat allele require higher doses of MPH for symptom improvement and symptom normalization, and suggested the possibility that the 7-repeat allele of the DRD4 gene VNTR polymorphism correlates with treatment outcome. Also a few previous studies have reported that the most frequent allele and genotype of DRD4 in the Korean population were the 4-repeat allele and 4/4, respectively. ${ }^{9,10)}$ One preliminary report suggested that ADHD children having the 7-repeat allele but not having a 4-repeat allele of the DRD4 exon-III VNTR polymorphism showed a worse response to treatment with MPH than ADHD children having the 4-repeat allele, owing to the decreased function of the $\mathrm{D} 4$ receptor. ${ }^{11)}$ It was particularly suggested that the 4-repeat allele at DRD4 could be a predictor of the response to treatment. The aim of the present study was to further investigate the association between the DRD4 VNTR polymorphism and treatment response in groups of ADHD and healthy controls children drawn from the genetically homogenous Korean population.

\section{METHODS}

\section{Subjects}

The patient group individuals were recruited from the ADHD outpatient clinic at the Child and Adolescent Psychiatric Division of the Psychiatric Department of Dankook University Hospital, Cheonan, Korea. We diagnosed ADHD according to the Diagnostic and Statistical Manual of Mental Disorders version IV (DSM-IV) ${ }^{12)}$ and Schedule for Affective Disorders and Schizophrenia for School-Age Children-Present and Lifetime Version (K-SADS-PL). ${ }^{13)}$ All the subjects were Korean. Subjects were excluded from the study if there was any evidence of conduct disorder, mood disorder, anxiety disorder, Tourette's syndrome, pervasive development disorder, mental retardation (IQ < 70) and neurological disorders, including epilepsy. All the interviews were done by a well-trained child psychiatrist. The ADHD patients were administered the Attention-deficit Diagnosis System (ADS), the Korean version of the modified computerized test of variables of attention (TOVA) for obtaining the accurate diagnosis. ${ }^{14)}$ The Korean version of the Conner's rating scales were used in the present study to obtain parental reports of their children's behavior. ${ }^{15)}$ Subjects were included from our sample if they had a score over two standard deviations from the norm on the tests for ADS (T-score > 70). ADHD had a lot of cormorbid disorders, as depressive disorder and anxiety disorder. So we excluded children with the high score of depressive symptoms and anxiety symptoms. Subjects with high anxiety scores (Spielberger trait/state anxiety scale score $>47 / 49$ ) on the Korean version of Spielberger trait-state anxiety scale for children ${ }^{16)}$ were excluded, and subjects with high depression scores (Kovacs depression inventory score $>29$ ) on Kovacs depression inventory for children ${ }^{17)}$ were also excluded. In this study we used as control group with no psychiatric disorder. These include 84 elementary students from Pyeongtaek in Korea, about 200,000 populations, screened to exclude depression, anxiety disorder, ADHD. Finally, 198 members that consisted of the affected children (114) and volunteers for normal control (84) were included in our study.

The efficacy measure was defined as a change in scores on the Korean ADHD Rating Scale (K-ARS) ${ }^{18)}$ and Clinical Global Impression (CGI) score ${ }^{19)}$ over time. The mean changes in the K-ARS, CGI severity score from baseline (week 0) to the end of treatment (week 8) and CGI improvement score (week 8) were also evaluated.

\section{Procedures}

The study protocol was approved by the institutional review board, and written informed consent was obtained. After structured interview, physical examination, and laboratory testing, eligible participants were assigned to drug. OROS MPH was dosed using a forced titration strategy starting at $18 \mathrm{mg} /$ day and increased weekly in 9 $\mathrm{mg}$ /day increments, the maximum dose being $36 \mathrm{mg} /$ day based on tolerability. No other psychotropic medications were permitted during the study. Efficacy and safety evaluations were also performed at baseline and 8 weeks.

\section{DNA Extraction and Genotyping}

Standard high salt extraction methods were used to isolate DNA from the whole blood lymphocytes. The primer sequence used to amplify the 48 base pair sequence of the VNTR polymorphic loci were the same as previously reported. ${ }^{20)}$ Thirty-five cycles were conducted that consisted of denaturation at $94^{\circ} \mathrm{C}$ for $60 \mathrm{sec}$, annealing at $60^{\circ} \mathrm{C}$ for $60 \mathrm{sec}$ and extension at $72^{\circ} \mathrm{C}$ for $60 \mathrm{sec}$. An initial denaturing step at $94^{\circ} \mathrm{C}$ for $10 \mathrm{~min}$ and a last extension step at $72^{\circ} \mathrm{C}$ for $10 \mathrm{~min}$ were also added. The reaction volumes were $50 \mathrm{ml}$, and they consisted of $0.1 \mu \mathrm{g}$ of genomic DNA, 10 pmol of each primer, $10 \mathrm{mM}$ dNTPs, 0.5 Unit Taq polymerase, 10 Taq buffer and distilled water. $8 \mu \mathrm{l}$ of PCR products were run on $8 \% \mathrm{TAE}(0.04 \mathrm{M}$ Tris-acetate, $0.01 \mathrm{M}$ EDTA) agarose gel. The amplified PCR products 
were electrophoresised at 50 volt for 1 hour $20 \mathrm{~min}$; they were stained with Ethidium bromide solution and visualized under UV light.

\section{Statistical Analysis}

The allele, genotype frequencies, and CGI improvement scores were compared using the chi-square test for the case control comparison analyses and CGI severity scores and K-ARS were compared using the t-test, using the SPSS program ver. 15.0 (SPSS Inc., Chicago, IL, USA). Statistical significance was set at $\mathrm{p}$ values less than 0.05 .

\section{RESULTS}

\section{Demographic Characteristics of the Subjects}

Of the total 114 cases with ADHD group, 90 (78.9\%) were boys and $24(21.1 \%)$ girls. Their ages ranged from 6 years to 14 years with a mean age of $8.9 \pm 2.2$ (standard deviation, SD) years. Abbreviated Conners' scale mean score was $18.9 \pm 3.3$ (SD). Of the total 84 cases with control group, 51 (60.7\%) were boys and 33 (39.3\%) girls. Their ages ranged from 6 years to 14 years with a mean age of $10.2 \pm 1.3$ (SD) years, abbreviated Connors' scale mean score was $5.9 \pm 4.5$ (SD).

\section{Comparison of the Frequency of the Genotypes and Alleles with Genetic Polymorphism between the Control Group and the ADHD Group}

Genotype frequencies in the ADHD sample were $0.9 \%$ $2 / 2$ repeats, $0.9 \% 2 / 3$ repeats, $21.9 \% 2 / 4$ repeats, $1.8 \% 2 / 6$ repeats, $0.9 \% 3 / 4$ repeats, $69.3 \% 4 / 4$ repeats, $4.4 \% 4 / 5$ repeats. Genotype frequencies of the control sample were $2.4 \% 2 / 2$ repeats, $34.5 \% 2 / 4$ repeats, $1.2 \% 2 / 6$ repeats, $57.1 \% 4 / 4$ repeats, $4.8 \% 4 / 5$ repeats $\left(\chi^{2}=6.24\right.$, degree of freedom $[\mathrm{df}]=6, p=0.40)$. In otherwise the $4 / 4$ genotype frequencies in the ADHD sample were $69.3 \%$, non $4 / 4$ genotype frequencies were $30.7 \%$. The $4 / 4$ genotype frequencies in the control sample were $57.1 \%$, non $4 / 4$ genotype frequencies were $42.9 \%$. The chi-square test result suggested that the $4 / 4$ repeats genotype was borderline significantly higher trend in ADHD children than the non $4 / 4$ repeats genotype $\left(\chi^{2}=3.11, \mathrm{df}=1, p=0.08\right)$ (Table 1$)$. Genotype frequencies of DRD4 were consistent with those expected under Hardy-Weinberg equilibrium (HWE).

Allele frequencies in the ADHD sample were $13.2 \% 2$ repeats, $0.9 \% 3$ repeats, $82.9 \% 4$ repeats, $2.2 \% 5$ repeats, $0.9 \% 6$ repeats. Allele frequencies of the control sample were $20.2 \% 2$ repeats, $76.8 \% 4$ repeats, $2.4 \% 5$ repeats,
Table 1. Comparison between the $4 / 4$ genotype at DRD4 genotype

\begin{tabular}{lllll}
\hline \multirow{2}{*}{ Rating scale } & \multicolumn{2}{c}{ Genotype, $\mathrm{n}(\%)$} & \multirow{2}{*}{$\chi^{2}$} & $p$ value* \\
\cline { 2 - 3 } & Control & ADHD & & \\
\hline The 4/4 genotype & $48(57.1)$ & $79(69.3)$ & 3.11 & 0.08 \\
The non 4/4 genotype & $36(42.9)$ & $35(30.7)$ & & \\
\hline
\end{tabular}

$\chi^{2}$-test by Fisher's exact test, *If $p<0.05$ is a significant, and if $p>0.05, p<0.1$ is a borderline significant.

$0.6 \% 6$ repeats. The chi-square test result suggested that the 4 repeats allele was not significant in ADHD children than the non 4 repeats allele $\left(\chi^{2}=2.28, \mathrm{df}=5, p=0.13\right)$.

\section{Comparison of the CGI Improvement with Genetic Polymorphism between the Control Group and the ADHD Group}

According to the CGI improvement of children as assessed by their parents, we found that $74.7 \%$ of subjects with the $4 / 4$ genotype at DRD4 showed a good response (above moderate improvement) to OROS MPH treatment, but $74.3 \%$ of subjects with the non $4 / 4$ genotype at DRD4 showed a good response to MPH treatment $\left(\chi^{2}=1.47\right.$, $\mathrm{df}=1$, and $p=0.68$ ). The CGI severity score of the ADHD subjects with $4 / 4$ genotype decreased from $5.1 \pm 0.8$ (base) to $3.4 \pm 1.3$ ( 8 weeks), the ADHD subjects with non $4 / 4$ genotype decreased from $5.0 \pm 0.9$ (base) to $3.2 \pm 1.3$ ( 8 weeks) respectively at baseline (t-test value $=0.91$, $p=0.34$ ) and after 8 weeks ( $\mathrm{t}$-test value $=0.33, p=0.57$ ) of MPH treatment (Table 2). Also the K-ARS overall score of the ADHD subjects with 4/4 genotype decreased from $30.1 \pm 7.3$ (base) to $18.3 \pm 6.0$ ( 8 weeks), the ADHD subjects with $4 / 4$ genotype decreased from $29.5 \pm 8.6$ (base) to $18.5 \pm 6.8$ ( 8 weeks) respectively at baseline (t-test val$\mathrm{ue}=0.10, p=0.75)$ and after 8 weeks (t-test value $=0.03$, $p=0.87$ ) of MPH treatment (Table 2).

\section{DISCUSSION}

There have been few studies that defined the association of ADHD and the 4-repeat allele of DRD4. Barr et al. ${ }^{21)}$ conducted a transmission disequilibrium test (TDT) analysis to determine the association between ADHD and DRD4 and found significant evidence for the transmission of the 7-repeat allele and nontransmission of the 4-repeat allele. Leung et al. $^{5)}$ have compared the transmitted/not transmitted groups of 32 Chinese ADHD children and their family by using the TDT; they detected a significant difference in the 4-repeat allele of DRD4. Kim et al. ${ }^{6}$ reported a nonsignificant association between the DRD4 exon III 
Table 2. Comparison between the $4 / 4$ genotype at DRD4 and the response of the ADHD children to the drug treatment according to the CGI, K-ARS

\begin{tabular}{|c|c|c|c|c|c|c|}
\hline \multirow{2}{*}{ Rating scale } & \multicolumn{2}{|c|}{ CGI improvement* } & \multicolumn{2}{|c|}{ CGI severity } & \multicolumn{2}{|c|}{ K-ARS total } \\
\hline & Poor & Good & Base $^{\dagger}$ & 8 weeks $^{\dagger}$ & Base $^{\S}$ & 8 weeks \\
\hline ADHD with $4 / 4$ genotype & $20(25.4)$ & $59(74.7)$ & $5.1 \pm 0.8$ & $3.4 \pm 1.3$ & $30.1 \pm 7.3$ & $18.3 \pm 6.0$ \\
\hline ADHD with non $4 / 4$ genotype & $9(25.7)$ & $26(74.3)$ & $5.0 \pm 0.9$ & $3.2 \pm 1.3$ & $29.5 \pm 8.6$ & $18.5 \pm 6.8$ \\
\hline
\end{tabular}

Values are presented as number (\%) or mean \pm standard deviation. * The $\chi^{2}$-test (by Fisher's exact test) value=1.47; degree of freedom=1, $p$ value $=0.69 ;{ }^{\dagger}$ Student's t-test value $=0.91, p=0.34 ;{ }^{\ddagger}$ Student's t-test value $=0.33, p=0.57 ;{ }^{\S}$ Student's t-test value=0.10, $p=0.75 ;$ " Student's t-test value=0.03, $p=0.87 . p<0.05$. DRD4, dopamine receptor D4; ADHD, attention deficit hyperactivity disorder; CGI, Clinical Global Impression; K-ARS, Korean ADHD Rating Scale.

48-bp VNTR polymorphism and 126 Korean ADHD children and their family by using the TDT. Also Cheon et $_{\text {al. }}{ }^{22)}$ detected a significant association between the DRD4 exon III 48-bp VNTR polymorphism and the response to MPH treatment in ADHD children. Those subjects homozygous for the 4-repeat allele at DRD4 showed a better response to MPH treatment than those who were not homozygous for this allele. In our study, the relation of the distribution of the DRD4, drug response and ADHD was examined, and an association was not detected. These findings are relatively not consistent with the preliminary results of Sallee et al. ${ }^{11)}$ study and Cheon et al. ${ }^{22)}$ study in Korea. Though there was a nonsignificant difference of DRD4 genotype frequencies between patient group and control group, there was not a difference in DRD4 allele frequencies. Such a result can suggest that ADHD is not associated with the polymorphism of the DRD4 gene in Koreans. However, since our result was obtained from a very small number, it is not reasonable to consider that this result represents all the ADHD children and their families in Korea. It has also been suggested that ADHD is a polygenic disorder and that genes involved in the metabolism of dopamine, norepinephrine, and other neurotransmitters may only contribute small phenotypic variance. Hence, it is difficult to make a conclusion. In addition, the result may have come about due to the heterogeneity of the various genes involved in ADHD. In other words, the point is that due to the expression of the various alleles of DRD4, by the multiple genetic interactions, a specific effect of a single gene may not be detected. Case control studies could also present population stratification. Otherwise family-based association methods could overcome this effect, particularly given the wide variation in the DRD4 allele among human populations. ${ }^{23)}$ In the studies performed by Swanson et al., ${ }^{23)}$ it has been reported that the polymorphism of the DRD4 candidate gene and ADHD disorder were not associated, and as the major causality of such a result, there is a difference for the distribution of the alleles among geographical regions and races. Due to these regional and racial differences, there could be wide differences for the frequency of alleles, and in our study, the frequency of the alleles in ADHD children was somewhat different from the frequency reported in other countries. The chi-square test result suggested that frequencies of the 4 repeats allele and CGI improvement scores were not significant in ADHD children than the non 4 repeats allele. However, larger sample size is necessary for controlling the confounding factors. Lastly, the relatively small sample size limits the generalization of our findings.

The limitations of our study are that first, the number of the study subjects was small, due to the power of our sample. The study was performed on 114 children who were diagnosed at outpatient clinics and the 84 normal control group. However, it was a small number, and so the range of statistical errors may be large. Second, in our study, the comparison with family group was not performed; thus, it could not be considered that the difference of the distribution from other races with checking the distribution of a normal group. Although our study population is composed of single ethnicity-Koreans, as was our previous genetic study in Korean children, ${ }^{6)}$ our study's case control design may have a more diverse population. In our study, the comparison was performed with applying the case control method that do not considered the genetic influence within a family, and so the false negative results were increased.

Future gene association studies could be anticipated in the pure ADHD group with excluding comorbid disorder, in male children only, in the subtype of the hyperactive behavior group, in the group that responded well to MPH. ${ }^{24)}$ In the future, a study comparing the clinical differences in a larger number of ADHD patients by classifying them into small groups is required.

\section{REFERENCES}

1. Faraone SV, Sergeant J, Gillberg C, Biederman J. The worldwide prevalence of $A D H D:$ is it an American con- 
dition? World Psychiatry 2003;2:104-113.

2. Santosh PJ, Taylor E. Stimulant drugs. Eur Child Adolesc Psychiatry 2000;9(Suppl 1):I27-I43.

3. Gelernter J, Kennedy JL, van Tol HH, Civelli O, Kidd KK. The D4 dopamine receptor (DRD4) maps to distal 11p close to HRAS. Genomics 1992;13:208-210.

4. LaHoste GJ, Swanson JM, Wigal SB, Glabe C, Wigal T, King $\mathrm{N}$, et al. Dopamine D4 receptor gene polymorphism is associated with attention deficit hyperactivity disorder. Mol Psychiatry 1996;1:121-124.

5. Leung PW, Lee CC, Hung SF, Ho TP, Tang CP, Kwong $\mathrm{SL}$, et al. Dopamine receptor D4 (DRD4) gene in Han Chinese children with attention-deficit/hyperactivity disorder $(A D H D)$ : increased prevalence of the 2-repeat allele. Am J Med Genet B Neuropsychiatr Genet 2005;133B:54-56.

6. Kim YS, Leventhal BL, Kim SJ, Kim BN, Cheon KA, Yoo $\mathrm{HJ}$, et al. Family-based association study of DAT1 and DRD4 polymorphism in Korean children with ADHD. Neurosci Lett 2005;390:176-181.

7. Seeger G, Schloss P, Schmidt MH. Marker gene polymorphisms in hyperkinetic disorder-predictors of clinical response to treatment with methylphenidate? Neurosci Lett 2001;313:45-48.

8. Hamarman S, Fossella J, Ulger C, Brimacombe M, Dermody J. Dopamine receptor 4 (DRD4) 7-repeat allele predicts methylphenidate dose response in children with attention deficit hyperactivity disorder: a pharmacogenetic study. J Child Adolesc Psychopharmacol 2004;14:564-574.

9. Lee HJ, Lee HS, Kim YK, Kim L, Lee MS, Jung IK, et al. D2 and D4 dopamine receptor gene polymorphisms and personality traits in a young Korean population. Am J Med Genet B Neuropsychiatr Genet 2003;121B:44-49.

10. Lee HJ, Lee HS, Kim YK, Kim SH, Kim L, Lee MS, et al. Allelic variants interaction of dopamine receptor D4 polymorphism correlate with personality traits in young Korean female population. Am J Med Genet B Neuropsychiatr Genet 2003;118B:76-80.

11. Sallee FR, Newcorn JA, Allen AJ, Stein MA, McDougle C, Sethuraman S. Pharmacogenetics of atomoxetine: relevance of DRD4. In: Scientific Proceedings of the 51st annual meeting of American Academy of Child and Adolescent Psychiatry; 2004; Washington, DC.

12. American Psychiatric Association. Diagnostic and statistical manual of mental disorders, 4th ed. Washington, DC:American Psychiatric Association;1994.

13. Kim YS, Cheon KA, Kim BN, Chang SA, Yoo HJ, Kim JW, et al. The reliability and validity of Kiddie-Schedule for Affective Disorders and Schizophrenia-Present and Lifetime Version-Korean version (K-SADS-PL-K). Yonsei Med J 2004; 45:81-89.

14. Shin MS, Cho SC, Chun SY, Hong KE. A study of the development and standardization of ADHD diagnostic system. Korean J Child Adolesc Psychiatry 2000;11:91-99.

15. Oh KJ. Parent training treatment effect study in Korean ADHD patients. J Korean Soc Clin Psychol 1994;13:217233.

16. Cho SC, Choi JS. Development of Korean form of the statetrait anxiety inventory for children. J Seoul Psychitr 1989; 14:150-157.

17. Kovacs M. The children's depression inventory: A self-rated depression scale for school-aged youngsters. Unpublished manuscript, University of Pittsburgh;1983.

18. Kim YS, So YK, Noh JS, Choi NK, Kim SJ, Koh YJ. Normative data on the Korean ADHD Rating Scales (K-ARS) for parents and teacher. $J$ Korean Neuropsychiatr Assoc 2003;42:352-359.

19. Guy W. ECDEU Assessment Manual for Psychopharmacology, Revised. Bethesda:US Department of Health, Education, and Welfare; 1976.

20. Holmes J, Payton A, Barrett JH, Hever T, Fitzpatrick H, Trumper AL, et al. A family-based and case-control association study of the dopamine D4 receptor gene and dopamine transporter gene in attention deficit hyperactivity disorder. Mol Psychiatry 2000;5:523-530.

21. Barr CL, Wigg KG, Bloom S, Schachar R, Tannock R, Roberts $\mathrm{W}$, et al. Further evidence from haplotype analysis for linkage of the dopamine D4 receptor gene and attentiondeficit hyperactivity disorder. Am J Med Genet 2000;96:262267.

22. Cheon KA, Kim BN, Cho SC. Association of 4-repeat allele of the dopamine D4 receptor gene exon III polymorphism and response to methylphenidate treatment in Korean ADHD children. Neuropsychopharmacology 2007;32:1377-1383.

23. Swanson JM, Sunohara GA, Kennedy JL, Regino R, Fineberg E, Wigal T, et al. Association of the dopamine receptor D4 (DRD4) gene with a refined phenotype of attention deficit hyperactivity disorder (ADHD): a family-based approach. Mol Psychiatry 1998;3:38-41.

24. Tahir E, Yazgan Y, Cirakoglu B, Ozbay F, Waldman I, Asherson PJ. Association and linkage of DRD4 and DRD5 with attention deficit hyperactivity disorder (ADHD) in a sample of Turkish children. Mol Psychiatry 2000;5:396-404. 